\title{
Design of Neural Network Based Expert System for Automated Lime Kiln System
}

\author{
Krishna Anand ${ }^{1}$, Elliriki Mamatha ${ }^{2 *}$, Chandra S. Reddy ${ }^{3}$, Mani Prabha $^{4}$ \\ ${ }^{1}$ Dept of Computer Science, Sreenidhi Institute of Technology, Hyderabad 501301, India \\ ${ }^{2}$ School of Science, GITAM University, Bangalore Campus 561203, India \\ ${ }^{3}$ Dept of Mathematics, CIT- North Campus, Bangalore 562110, India \\ ${ }^{4}$ School of Computing, SASTRA University, Thanjavur 613401, India
}

Corresponding Author Email: sricsrmax@gmail.com

https://doi.org/10.18280/jesa.520406

Received: 23 April 2019

Accepted: 9 July 2019

\section{Keywords:}

artificial neural network, optimization, lime kiln, shell temperature, furnace oil consumption, intelligent controller

\begin{abstract}
Rotary lime kiln is an important pulp production facility of paper mills and cement factories. To achieve fully-automated lime kiln production, this paper firstly carries out a thorough review of the production processes of lime kiln, revealing that the shell temperature of lime kiln and furnace oil consumption are two key parameters to the working efficiency and product quality of the kiln. Next, an expert system was designed based on artificial neural network to optimize the parameters in kiln application. The functions and operations of the intelligent controllers in the system were also detailed. After that, the designed system was adopted to predict the shell temperature and furnace oil consumption using moisture in lime mud. The comparison between the predicted results and the real-time data of a plant shows that our system can predict the two key parameters accurately, enabling the operator to make sound decisions on many production indices. The research findings lay the basis for low-cost and high-quality lime kiln operations.
\end{abstract}

\section{INTRODUCTION}

The expected benefits of Rotary lime kiln related to the pulp and paper mills and cement industry deal with reduction in fuel consumption, improvement in kiln stability, providing better control of waste fuels, providing maximizing product output, reduction in power consumption and production of consistent product lime quality [1-4]. Unlike in cement plants, productivity in terms of lowered specific fuel consumption and high product quality in Rotary Lime kiln is dependent on various parameters which are complex in their inter-relationship [5, 6]. Based on 80-20 Pareto Law model, for any problem, it is known that $20 \%$ of the factors account for $80 \%$ of the problems. Hence, it is desirable to identify the parameters of interest.

The characteristics of Lime mud feed play a pivotal role as can be appreciated from brief of the process. The automation of the lime kiln is achieved by process measurements, accurate and repeatable process controllers followed by its successful implementation [7]. The lime product from the kiln is dependent on a large number of factors right from feed materials and practically impossible to predict the furnace oil consumption and the purity of lime [8]. The furnace oil consumption is dependent not only on the lime mud input load but also on moisture content in feed.

The lack of total Kiln automation significantly affects the performance of the kiln. Kiln operations are optimized by expert system inbuilt with neural network [9]. In this paper, the following parameters have been used namely Lime Mud, Make-up Lime Stone, Flue gas Temperature, Oxygen, Product Lime, Kiln Speed, Kiln shell and flue gas exit temperatures, Furnace oil consumption, Lime mud Moisture and ID fan Speed. Of the wide variety of outputs obtained, three of them (namely Kiln shell Temperature, Furnace oil and Lime Mud Moisture) have been taken into consideration for optimization. A separate neural network has been designed to predict the role of the various inputs in affecting each of the three outputs. The design consists of three intelligent controllers to evaluate kiln temperature, lime mud moisture and furnace oil consumption. Based on the output, the controllers periodically caution the operator to control furnace oil flow constantly and keeping the temperature of kiln output maintained between $190^{\circ} \mathrm{C}$ and $215^{\circ} \mathrm{C}$.

In early 1970's kiln systems are maintained manually and due to its complexity of the process, it is very difficult to maintain the process efficiently and harder to find the furnace oil efficiency. Hence, a modern and intelligent controller is required to increase the efficiency of the kiln process. Many researchers have been done since the early 1970 based on intelligent modelling approach. Initially, application of fuzzy logic to rotary kiln was carried out in 1978. Sweden pulp plant was then designed used fuzzy logic control system in 1979. Cement kiln model and measurement data are identified successfully in Qiqihar cement plant by using fuzzy control system which is implemented by Mengyong in 1988 [10]. Renganathan and Johnson [11] applied fuzzy method to identify the parameter and adaptive controller optimization in 1995. Constraint based fuzzy controller of kiln was designed by Chiang and Robert [12] in 2001.

Qin and Jia [13] introduced a Hierarchy Fuzzy Controller of Shuttle kiln combustion Process in 2002. Volglauer et al. [14] combined the upper Fuzzy controller with the lower model based closed loop controller in 2004. Integration of conventional loop control and intelligent control was proposed by $\mathrm{Wu}$ et al. [15], at North-eastern University Research centre of Automation in 2006. A fuzzy control in 
Greece TITAN cement plant, aiming at reducing NOx emission to atmosphere was introduced by Batzias [16] from Piraeus University in 2006. Fuzzy supervision controller and MLP neural network was designed by Fallahpour et al. [17] of Iran Tehran Science, Technology University in 2007. Many research work focus on neural network due to nonlinear, mapping, self learning ability [18]. Portuguese Dias et al. [19] used feed forward neural network to control rotary kiln in 2002. He designed control system using neural network structure that utilizes genetic algorithm at the same conference.

Neural network control system based on features of combustion flame was proposed by Li Shutao in the same year. Mamatha et al. [20] and Gao and Liu [21] used dual heuristic dynamic programming to address temperature control in 2016. Intelligent predictive control strategy applied to sintering temperature in rotary kiln based on image feedback was designed by Zhang et al. [22] in 2007. Expert system is also used to control the rotary lime kiln. Expert system transfers the task-specific knowledge from human to computer. Hybrid hierarchical control system was described by Hagemoen [23] in 1993. To stabilize the temperature field and to maximize the kiln performance, Chunhua Yang used expert hybrid reasoning in 2005. Several methods use neural network with control algorithm. Wang Yaonan presented hybrid intelligent control in 1996. These techniques combine expert control with a fuzzy neural network model. Neural network model with advanced high level controllers was presented by Jarvensivu et al. [24] in 2001. Fuzzy controller based on FCM clustering analysis and neural network was presented in the work by Anand et al. [25]. It is based on the idea of knowledge reduction of the rough sets (RS) theory and fuzzy neural network (FNN). Pattern-based hybrid intelligent control strategy was presented by Zhou and Chai [26] in 2007. The model is inaccurate even after the development of kiln process control. However a large number of constraints and many other problems regarding kiln control system continue to exist.

Expert systems have been widely used in medical applications more recent ones dealing with detecting asthma severity $[27,28]$. Section-2 outlines brief introduction to lime kiln evaluation processes. A wide degree of research has been carried out in lime kilns which have been highlighted in several conferences and journals. The design of expert system with neural network will be explained in section-3. Section-4 elucidates the discussion and analysis of the real time data and the evaluated data. Finally, the conclusions are given in section-5.

\section{LIME KILN EVALUATION PROCESS}

The objective of the Rotary Lime kiln in the 'Paper Plant' is to convert the Lime mud with high moisture content from the Mud disc filter to lime of high purity for the Recausticizer plant $[29,30]$. Lime mud of moisture in the range of $35 \%$ to $45 \%$ along with some quantity of make-up fresh limestone is fed to the Rotary lime kiln rotating at a speed of 0.6 to 1.0 rpm.

Furnace oil is being used as fuel for converting Lime mud to lime of high purity. Combustion air is heated through heat recovery from the hot lime product leaving the lime kiln in Satellite Cooler as shown in Figure 1. The Cooler has ten arms through the inside of which combustion air is admitted in counter-current direction to the hot lime product, which in turn gets cooled $[31,32]$. The hot air is led to Lime kiln for combustion, whereas the cooled product lime is discharged to the belt conveyor and sent to Recausticizing unit via the slaker.

In this process $\mathrm{CO}_{2}$ from the Calcium carbonate in feed is removed along with flue gas through the stack attached to the lime kiln at the back-end. Electrostatic precipitator at the back-end of the kiln is primarily for removing the particulates in the flue gas. The product discharged shall be of high purity ( 80 to $81 \%$ as $\mathrm{CaO}$ ). Depending on the moisture in lime mud and the feed flow, the oil consumption would vary. Due to the varying complexities associated with Lime mud, properties cannot be measured online. The samples of feed and fuel oil have to be sent to in house mill laboratory for detailed analysis and composition [33]. The amount of time spent on the same is significant and the delay associated with estimating the actual value would not help in correcting other dependent parameters such as fuel and air flows and excess oxygen concentration in air supplied.

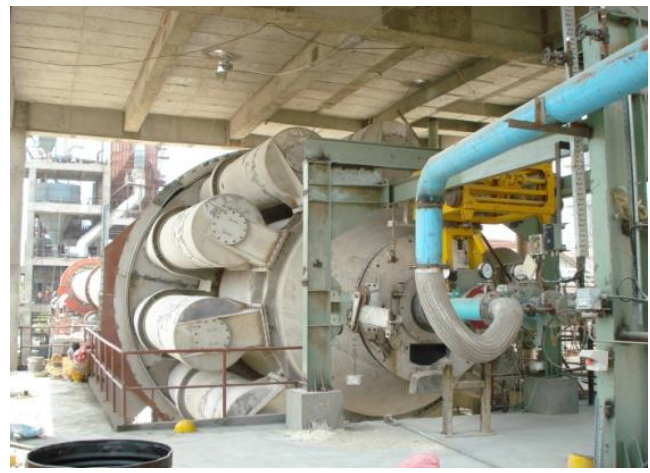

Figure 1. Satellite cooler with oil burner of rotary lime kiln

The disturbing effect due to variation in lime mud properties and the associated energy flux variation does not respond as feedback until known from the product output flow and quality. Neural Network based expert system would be the ideal tool to model the various complexities involved. Based on the past performance, output close to actual prediction shall be made; this feedback would be used to set the air flows. When compared with PID control, Neural Network control is expected to give better results; since it would reduce overshoot and minimize undershoot, when the process is subject to significant heat input load changes.

\section{DESIGN OF NEURAL NETWORK BASED EXPERT SYSTEM}

An expert system is a computer program that simulates the judgement and behaviour of a human or an organization that has expert knowledge and experience in a particular field. The expert systems are made up of three main components namely User Interface, Knowledge Base and Interface engine and it is given in Figure 2.

In this paper, the neural network based expert system is designed and it is used to obtain the optimization of parameters in a lime kiln application. The inference engine is able to handle considerable amount of conflict resolution; the prime factor being fuel consumption. Besides, other factors such as proven record of success, modern technology that is supported by factory engineers and operator friendliness must 
also be considered while selecting an expert system. An automated control unit of Lime kiln is a complex process because of multiple inter-related variables, non-linear reaction and varying process lags. It has been observed that the number of errors owing to operator's alertness and inefficiency has been on the increase. This expert system is able to automate the entire process by directly giving the action to be performed by the operator.

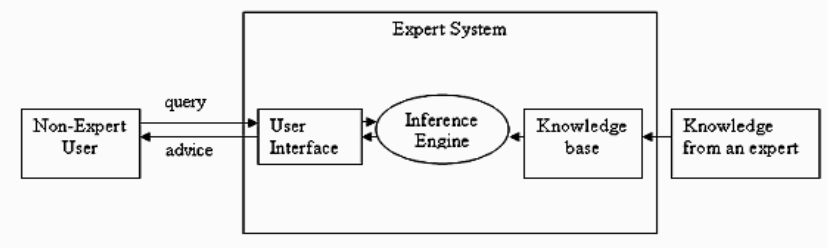

Figure 2. Components of an expert system

The detailed model of an expert system for a lime kiln process has been highlighted in Figure 3. For each individual kiln, expert systems are configured in order to meet the requirements. It helps the operator in many ways. The operators need not remember the long sequence of operations and related issues. Expert system provides better understanding of kiln operation and its performance. An expert system has been designed catering to soot blowing operations of a power plant. A similar expert system model using fuzzy logic concepts is being tried out for recovery boilers operating in power plants.

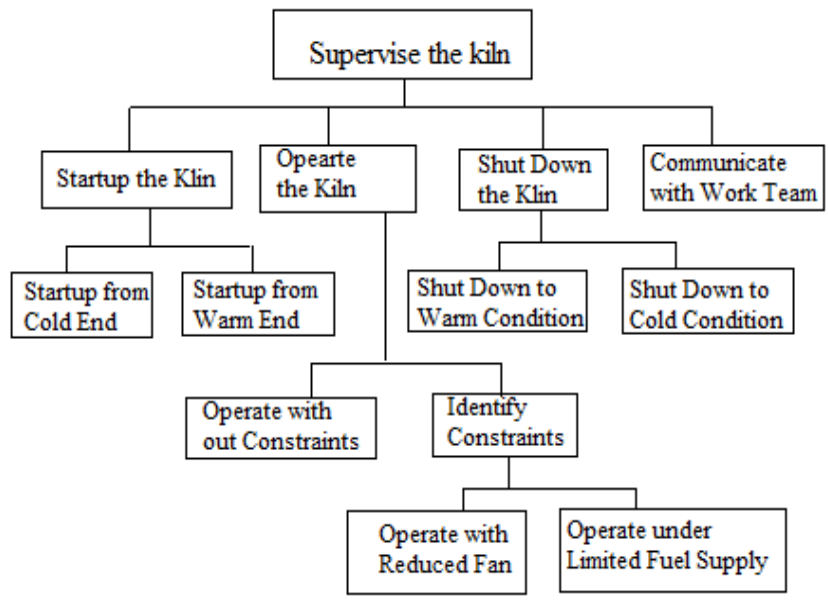

Figure 3. Expert model for lime kiln process

Skilled operators are used to control the process of the kiln, in order to maintain the balance between input raw material feed rate against fuel and to produce good quality product lime. Stability can be attained by general process or procedure discovered by the operator. Once the stable conditions are reached, production rate will be further improved. This system coupled with the backpropagation neural network discussed in the following section provides an insight into the way the amount of fuel consumed can be reduced thereby optimizing the entire process resulting in a considerable degree of savings for the industry.

\subsection{Artificial neural network}

Artificial Neural Networks are used to analyze and generalize the provided real time data, perform detailed analysis and make suitable predictions. The association from new data sets to old data can be made in a powerful way. The fast computation of solution can be obtained by Artificial Neural Network. The need for the network is to determine the relationship between a wide range of parameters and their influence in determining the amount of furnace oil consumption and kiln temperature. Once the relationship is obtained, the parameters could be suitably fine tuned to reduce the overall fuel oil consumption and also maintain the kiln shell temperature not exceeding $300{ }^{\circ} \mathrm{C}$. The constructed neural network consists of nine inputs and one output. Back propagation learning algorithm is used to optimize the parameters.

In the lime kiln process, the parameters namely Lime feed, Kiln shell temperature, Fuel consumption and Lime mud Moisture are highly volatile and it needs to control these variables by centralized automotive control unit using neural network based expert systems. Back propagation is the simplest algorithm and it performs higher level task such as prediction, decision making and classification. In this paper, the feed forward back propagation algorithm is used for predicting temperature of the kiln shell and flue gas outlet temperature, furnace oil consumption using moisture content in lime mud. It has an input layer, one or more hidden layers apart from one output layer. Training inputs are given to the input layer and desired outputs are compared at the output layer. The difference between the outputs is propagated to the previous layer. This aspect has been shown in Figure 4.

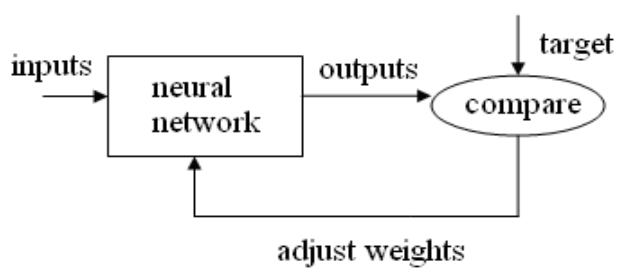

Figure 4. Learning model in an artificial neural network

\subsection{Design of intelligent controller in lime kiln systems}

A typical Lime kiln processes consists of primary and secondary or adjustable parameters. The primary parameters are Lime Mud Flow, Lime Stone Flow and Moisture Content in Lime Mud. The secondary parameters are air flow, ID fan speed, Kiln speed and furnace oil flow. The intelligent controller deals with predicting the values of the various outputs iteratively. The changes in values of product lime flow, product lime temperature, flue gas temperature and kiln shell temperature reflect the actual variations.

In this paper, the neural network based expert system is designed and it is used to obtain the optimization of parameters in a lime kiln application. The inference engine is able to handle considerable amount of conflict resolution; the prime factor being fuel consumption. Besides, other factors such as proven record of success, modern technology that is supported by factory engineers and operator friendliness must also be considered while selecting an expert system. An automated control unit of Lime kiln is a complex process because of multiple inter-related variables, non-linear reaction and varying process lags. It has been observed that the number of errors owing to operator's alertness and inefficiency has been on the increase. This expert system is able to automate the entire process by directly giving the action to be performed by the operator. 


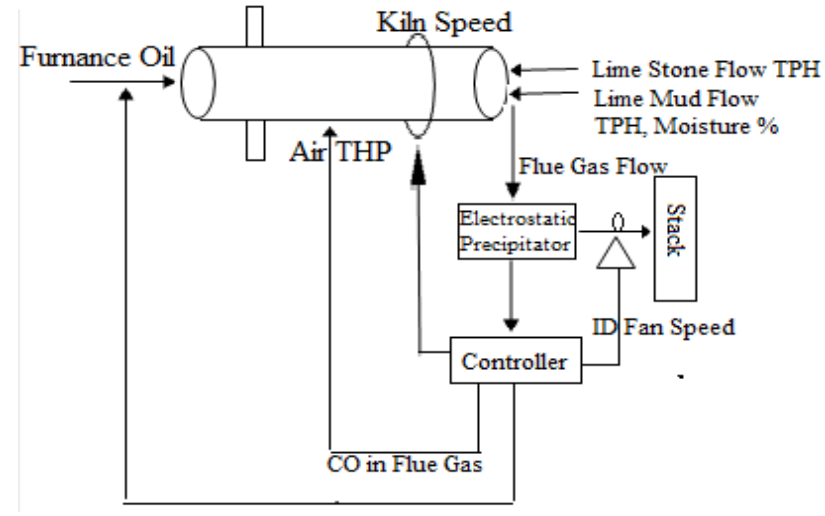

Figure 5. Lime kiln process

The Architecture of Intelligent Lime Kiln process is shown in Figure 6. It consists of three intelligent controllers (IC) namely IC1, IC2 and IC 3 . The primary aim of the controller is to produce a lime product of the best quality as soon as the operator changes any of the input parameters. The functionality of intelligent controller1 will control the kiln shell temperature between $195{ }^{\circ} \mathrm{C}$ and $210{ }^{\circ} \mathrm{C}$ by taking the primary and secondary input parameters dynamically. If the temperature goes beyond or below this range, the controller will automatically caution the operator and depending upon the requirement of temperature, the operator is either to increase or decrease the secondary parameters and if necessary, the operator can also change the primary parameters too.

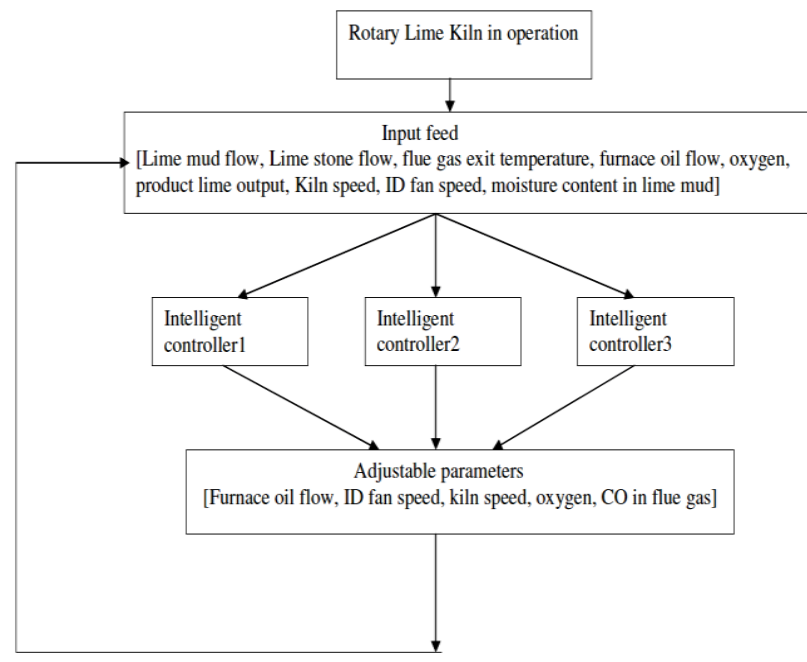

Figure 6. Architecture of intelligent lime kiln process

\subsection{Functionality of Intelligent Controller-1(IC 1$)$}

Intelligent Controller-1 is designed with neural network and $\mathrm{IC}_{1}$ accepts data directly from the lime kiln process. The functionality of neural network is explained as follows:

The Neural Network is trained with an input data pattern in order to predict the temperature of the kiln. Eight parameters namely Lime mud flow, lime stone feed rate, furnace oil consumption, kiln speed, ID fan speed, excess oxygen, flue gas exit temperature and product lime rate have been considered as input variables and kiln temperature is the only one neuron in the output layer. The designed neural network model is given in Figure 7.

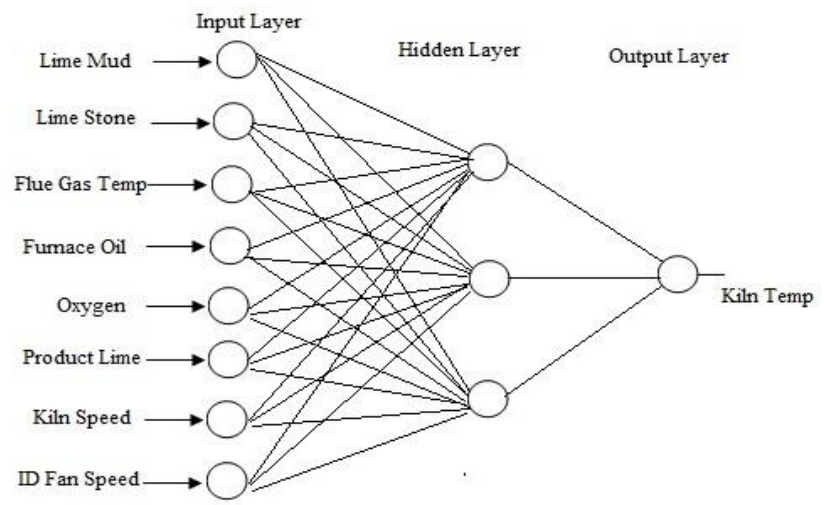

Figure 7. Predicting kiln temperature - neural network model

\subsubsection{Results and discussion}

The training, regression and performance charts (Error Chart) are given in Figure 8 to Figure 10. Figure 11 shows the comparison between the actual and the calculated value.

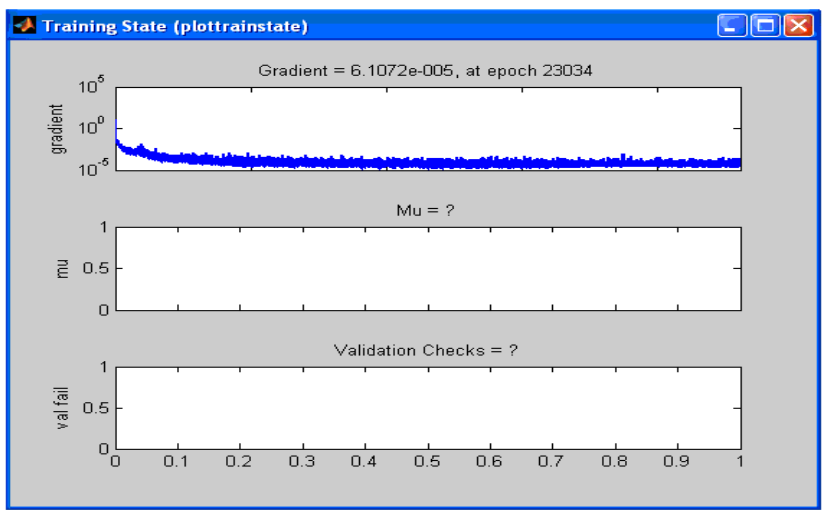

Figure 8. Training diagram

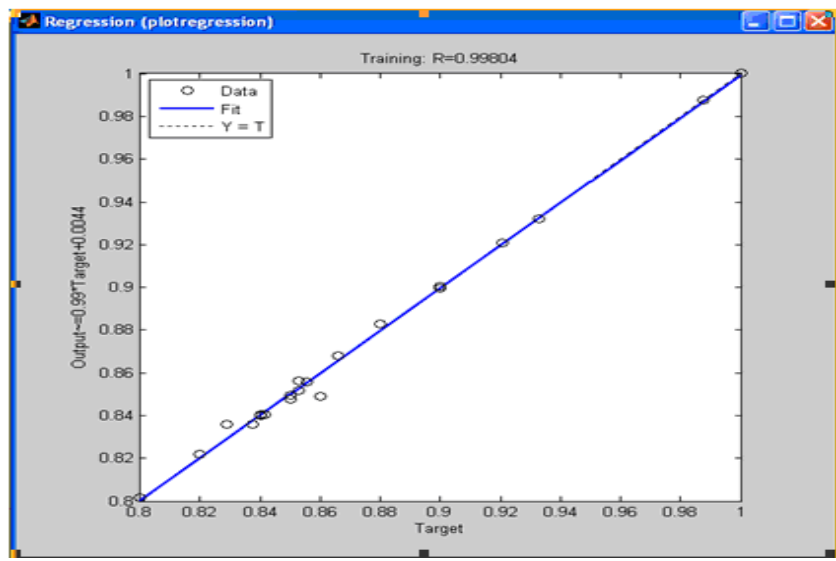

Figure 9. Regression diagram

Figures 8 to 10 show that the optimization is reached with an error limit of e- 05 and the regression analysis between the calculated value and the actual value will be 0.999 approximately. The control unit will monitor the flue gas exit temperature limit between 195 and $210{ }^{\circ} \mathrm{C}$ and when it will exceed the limit; automatically it will warn the people accordingly. If the temperature is maintained within the specified limit, the fuel requirement will be maintained constant. 


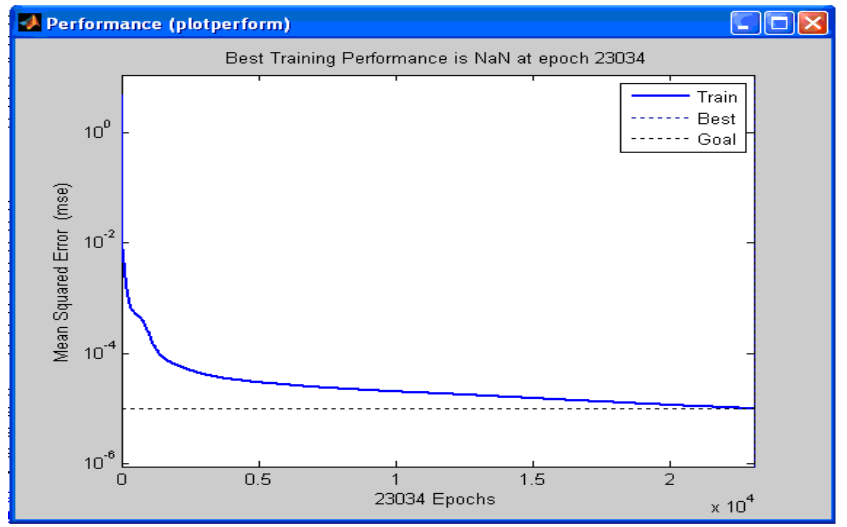

Figure 10. Error diagram

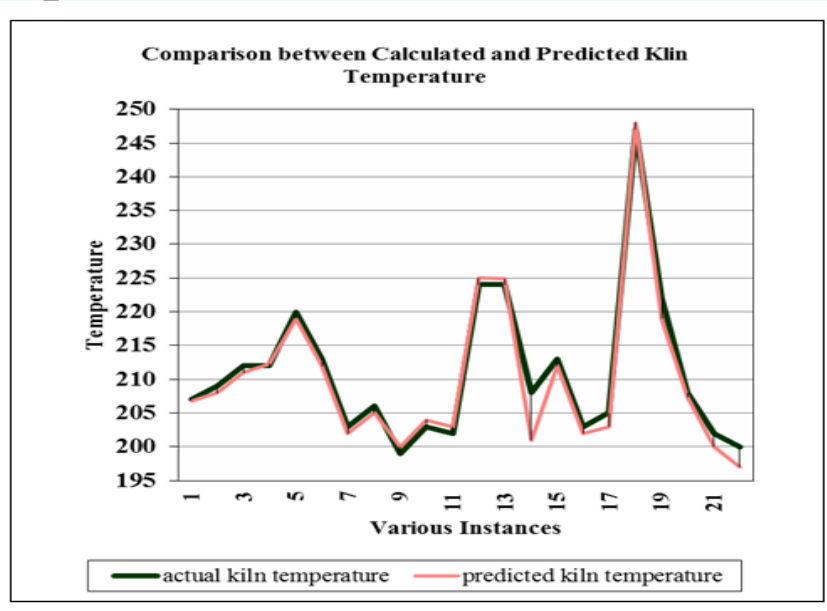

Figure 11. Performance graph for predicting kiln shell temperature

\subsection{Functionality of Intelligent Controller-2( $\left.\mathrm{IC}_{2}\right)$}

Intelligent Controller-2 $\left(\mathrm{IC}_{2}\right)$ is designed with neural network. $\mathrm{IC}_{2}$ accepts data directly from the lime kiln process. The neural network is able to suitably choose the number of hidden layers.

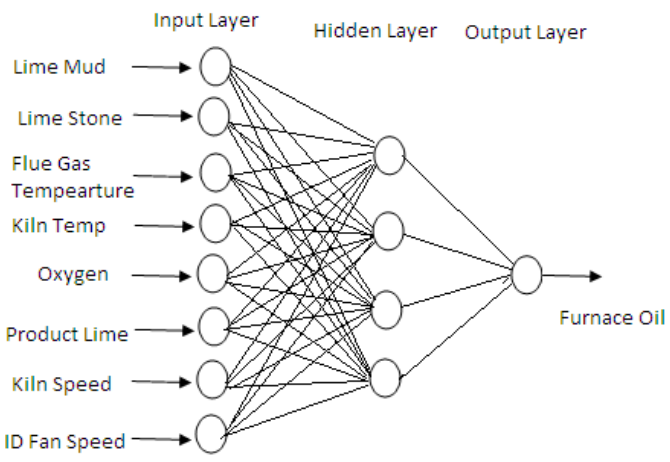

Figure 12. Neural Network model for predicting furnace oil consumption

The Neural Network is trained with an input data pattern in order to predict the furnace oil consumption. Eight parameters namely Lime mud flow, lime stone flow, Kiln shell temperature, kiln speed, ID fan speed, oxygen in air and flue gas temperature and product lime output have been considered as input variables and furnace oil is the only one neuron in the output layer. The designed neural network model is given in Figure 12.

\subsubsection{Results and discussion}

The training, regression and performance charts (Error Chart) are given in Figure 13 to Figure 15. The Figure 16 shows the comparison between the actual and the calculated furnace oil consumption.

Figures 13 to 15 show that the optimization is reached with an error limit of e-05 and the regression analysis between the calculated value and the actual value will be 0.999 approximately. The control unit will monitor the furnace oil limit between 0.80 and $0.94 \mathrm{kl}$, and if it exceeds the limit, automatically it will warn the people accordingly. If the furnace oil is maintained within the above limit, the kiln temperature will be maintained at a constant value.

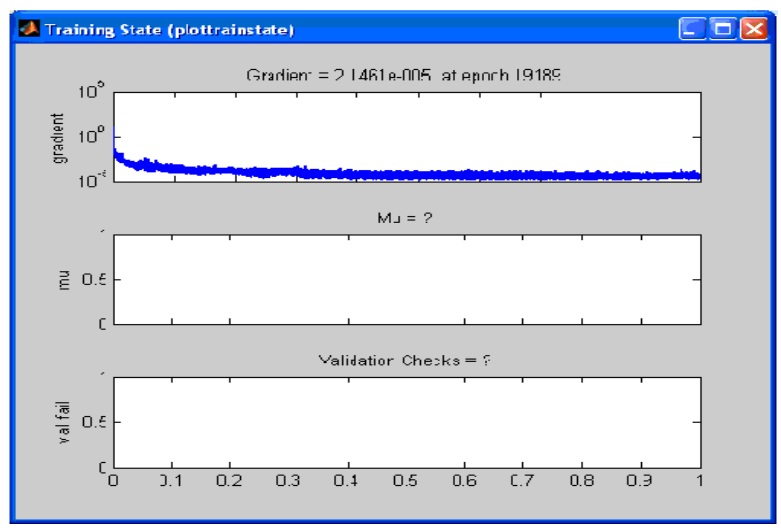

Figure 13. Training diagram

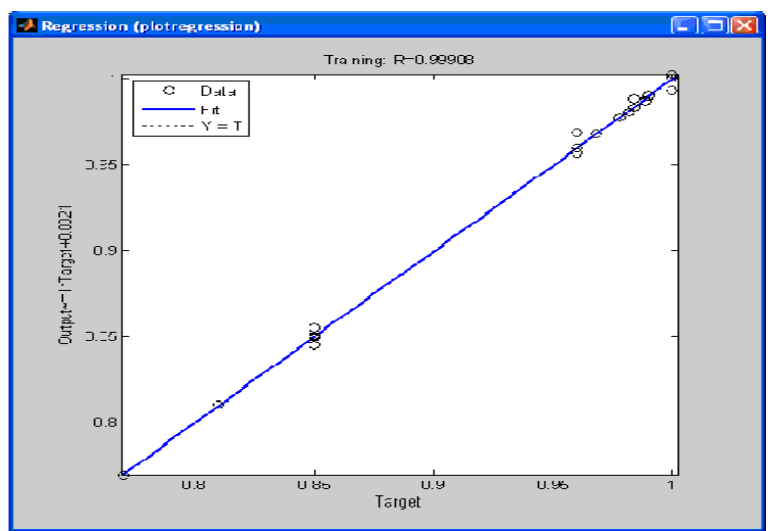

Figure 14. Regression diagram

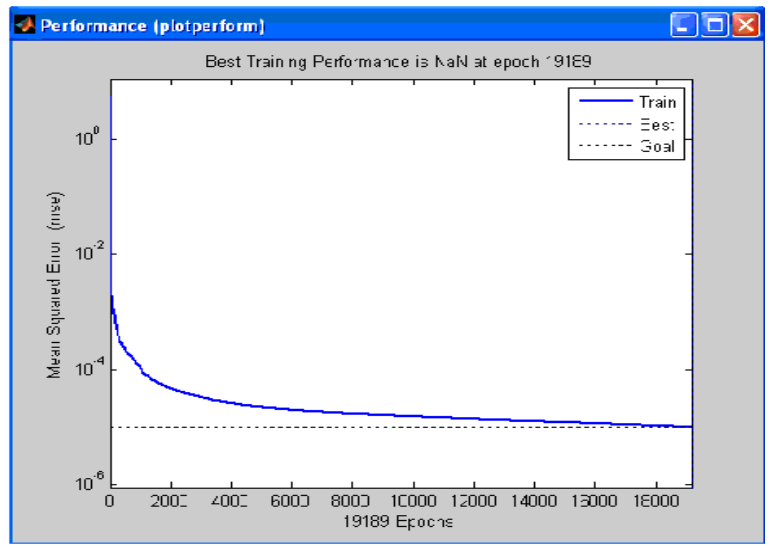

Figure 15. Error diagram 


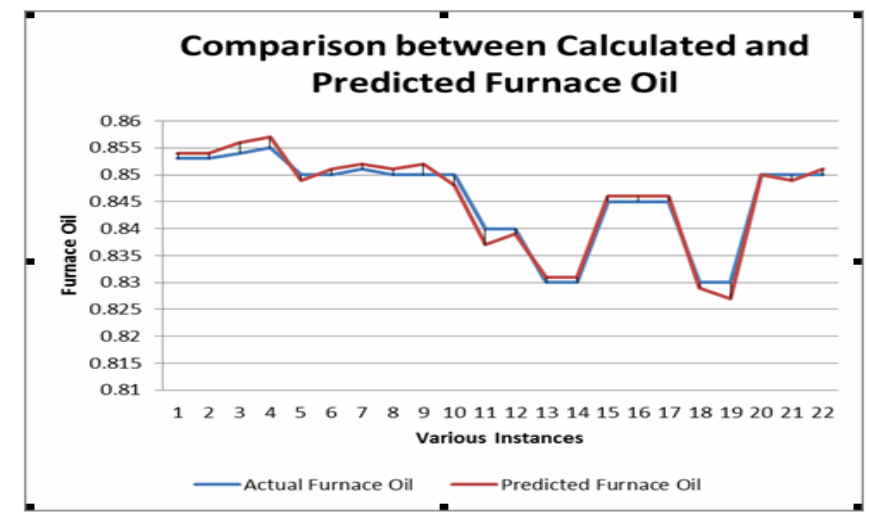

Figure 16. Performance graph for predicting furnace oil consumption

\subsection{Functionality of Intelligent Controller-3( $\left.\mathrm{IC}_{3}\right)$}

Intelligent Controller-3( $\left.\mathrm{IC}_{3}\right)$ is designed with neural network. $\mathrm{IC}_{3}$ accepts data directly from the lime kiln process.

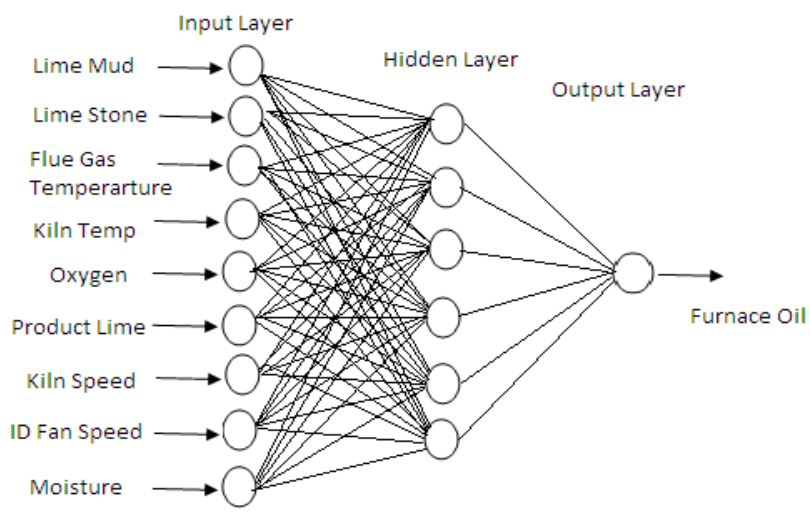

Figure 17. Neural Network model for predicting furnace oil consumption using moisture in lime mud

The Neural Network is trained with an input data pattern in order to predict the furnace oil consumption using moisture in lime mud. Nine parameters namely Lime mud, lime stone, Kiln Temperature, kiln speed, ID fan speed, oxygen, flue gas temperature, product lime and Lime mud moisture have been considered as input variables and furnace oil is the only one neuron in the output layer. The designed neural network model is given in Figure 17.

\subsubsection{Results and discussion}

The training, regression and performance charts (Error Chart) are given in Figure 18 to Figure 20. Figure 21 shows the comparison between the actual and the calculated furnace oil using moisture in lime mud.

The Figures 18 to 20 show that optimization is reached with an error limit of e-05 and the regression analysis between the calculated value and the actual value will be 0.99547 approximately. The control unit will monitor the furnace oil limit between 0.80 and $0.94 \mathrm{kl}$ and moisture range between 30 and $55 \%$. It has been observed that the maintenance of the kiln temperature largely depends on the level of control exhibited by moisture percentage and level of furnace oil.

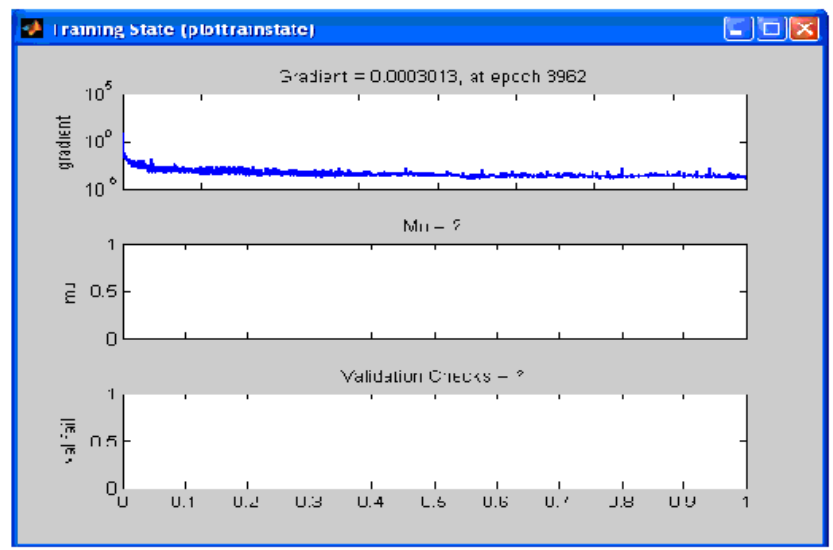

Figure 18. Training diagram

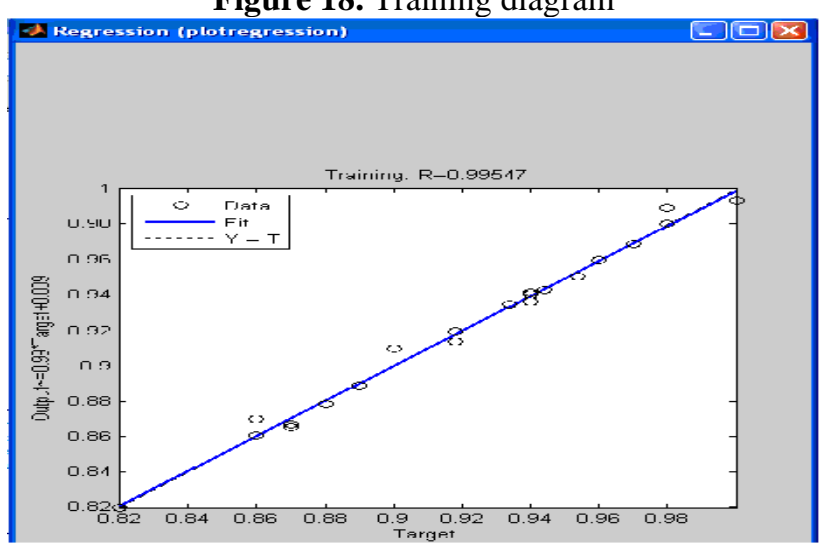

Figure 19. Regression diagram

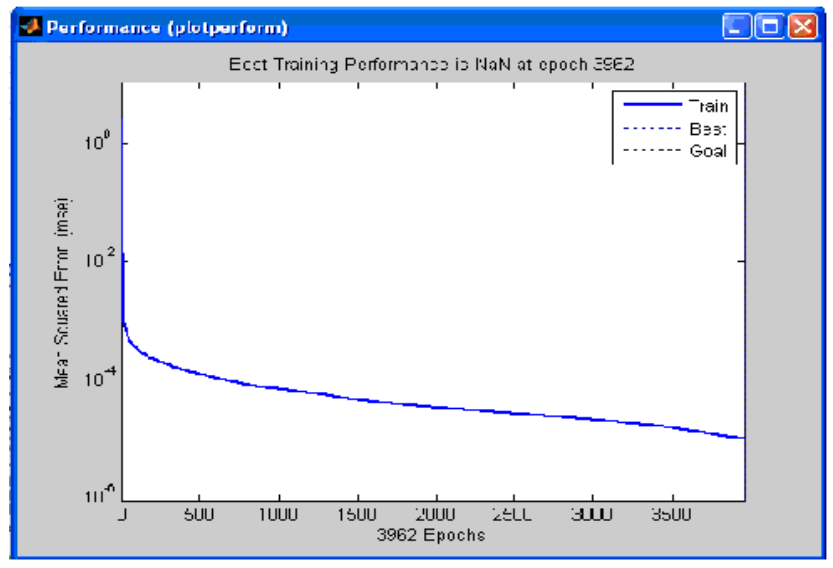

Figure 20. Error diagram

\section{CONCLUSIONS}

It could be easily observed that effective and reasonably accurate estimates of kiln shell temperature and furnace oil consumption can be obtained by the design of an Artificial Neural Network. The network has been trained to obtain a valid mathematical relationship between the provided set of inputs and the outputs. The designed network is able to determine the relationship in twenty three thousand and thirty four iterations. Finally, it has been inferred that the proposed expert system performs better than techniques illustrated in literature survey. 
This model helps the operator to take decisions on fixing the various parameters like lime stone feed, kiln temperature, flue gas exit temperature, moisture in lime mud in order to reduce the overall fuel consumption and also maximize lime production. The added advantages like reduction in operating cost and better refractory life makes this work viable.

Although the work carried out has been highly effective in identifying relationship between furnace oil consumption and kiln shell temperature, this work could be further extended by finding the relationship between kiln shell temperature and moisture. This in turn would add an additional dimension in the working of the plant. Besides, future researchers could also try to increase the number of hidden layers in the network and in turn try to find whether a further improvement could be obtained or not. At the same time, the factor of a rise in computational complexity in doing the same must not be ignored under any circumstances.

\section{REFERENCES}

[1] Imelainen, H., Loukiala, M. (2005). Lime kiln optimisation: Managing the inputs to stabilise the outcome. Appita Journal: Journal of the Technical Association of the Australian and New Zealand Pulp and Paper Industry, 58(4): 262.

[2] Alcántara, V., Cadavid, Y., Sánchez, M., Uribe, C., Echeverri-Uribe, C., Morales, J., Amell, A. (2018). A study case of energy efficiency, energy profile, and technological gap of combustion systems in the Colombian lime industry. Applied Thermal Engineering, 128: $393-401$ https://doi.org/10.1016/j.applthermaleng.2017.09.018

[3] Pani, A.K., Vadlamudi, V., Bhargavi, R.J., Mohanta, H.K. (2011). Neural network soft sensor application in cement industry: Prediction of clinker quality parameters. International Conference on Process Automation, Control and Computing, IEEE, pp. 1-6.

[4] Morvan, G., Veremme, A., Dupont, D., Jolly, D. (2009). Modélisation et conception multiniveau de systèmes complexes: stratégie d'agentification des organisations. Journal Européen des Systèmes Automatisés (JESA), 43(4-5): 381-406.

[5] Järvensivu, M., Juuso, E., Ahava, O. (2001). Intelligent control of a rotary kiln fired with producer gas generated from biomass. Engineering Applications of Artificial Intelligence, 14(5): 629-653.

[6] Sadeghian, M., Fatehi, A. (2011). Identification, prediction and detection of the process fault in a cement rotary kiln by locally linear neuro-fuzzy technique. Journal of Process Control, 21(2): 302-308. https://doi.org/10.1016/j.jprocont.2010.10.009

[7] Mamatha, E., Reddy, C.S., Prasad, K.R. (2016). Antialiased digital pixel plotting for raster scan lines using area evaluation. in emerging research in computing, information, communication and applications. Emerging Research in Computing, Information, Communication and Applications: ERCICA 2015, 3: 461-468. https://doi.org/10.1007/978981-10-0287-8_43

[8] Wu, J., Liu, C. (2018). A new pattern based Petri net to model sintering production process. Transactions of the Institute of Measurement and Control, 40(9): 2771-2778. https://doi.org/10.1177\%2F0142331217737834
[9] Subramanian, S., Sundara Raman, T.G., Krishna Anand, S. (2011). Fuzzy predictive control for intelligent soot blowing. European Journal of Scientific Research, 50(1): 135-142.

[10] Zhang, Li., Gao, X.W. (2009). Survey on rotary kiln process control. In 2009 Chinese Control and Decision Conference, Guilin, China. https://doi.org/10.1109/CCDC.2009.5191870

[11] Renganathan, S., Johnson, J.S. (1995). A robust adaptive controller using fuzzy logic approach. Proceedings of IEEE/IAS International Conference on Industrial Automation and Control, Hyderabad, India. https://doi.org/10.1109/IACC.1995.465861

[12] Chiang, D., Lai, R. (2001). A design methodology of constraint-based fuzzy logic controller. Proceedings Joint 9th IFSA World Congress and 20th NAFIPS International Conference (Cat. No. 01TH8569), Vancouver, BC, Canada. https://doi.org/10.1109/NAFIPS.2001.943728

[13] Qin, Y., Jia, L.M. (2002). Fuzzy hybrid control and its applications in complex combustion processes. In Proceedings 2002 IEEE International Conference on Artificial Intelligence Systems (ICAIS 2002), Divnomorskoe, https://doi.org/10.1109/ICAIS.2002.1048057

[14] Voglauer, B., Grausam, A., Jörgl, H.P. (2004). Reaction-kinetics of the vanadium roast process using steel slag as a secondary raw material. Minerals Engineering, $\quad$ 17(2): 317-321. https://doi.org/10.1016/j.mineng.2003.10.032

[15] Wu, Y.J., Zhou, X.J., Chai, T.Y., Yue, H. (2006). Design and application of intelligent control system of a rotary kiln process for alumina production. Journal of East China University of Science and Technology, 32(7): 745-749. https://doi.org/10.1016/j.applthermaleng.2017.09.018

[16] Batzias, F.A. (2006). Rotary Cement kiln control for reducing NOx emissions to atmosphere. 2006 IEEE Conference on Emerging Technologies and Factory Automation, Prague, Czech Republic. https://doi.org/10.1109/ETFA.2006.355361

[17] Fallahpour, M., Fatehi, A., Araabi, B.N., Azizi, M. (2007). A supervisory fuzzy control of back-end temperature of rotary cement kilns. 2007 International Conference on Control, Automation and Systems, Seoul, South https://doi.org/10.1109/ICCAS.2007.4406944

[18] Krishna Anand, S., Sundara Raman, T.G., Subramanian, S. (2011). Incorporating supervisory learning through type -2 fuzzy expert system for increasing productivity of a boiler. CiiT International Journal of Fuzzy Systems, 3(8).

[19] Dias, F.M., Antunes, A., Mota, A.M. (2002). Automating the construction of neural models for control purposes using genetic algorithms. IEEE 2002 28th Annual Conference of the Industrial Electronics Society. IECON 02, Sevilla, Spain. https://doi.org/10.1109/IECON.2002.1185282

[20] Mamatha, E., Reddy, C.S., Anand, S.K. (2016). Focal point computation and homogeneous geometrical transformation for linear curves. Perspectives in Science, 8: 19-21. https://doi.org/10.1016/j.pisc. 2016.01.006

[21] Gao, Y., Liu, Y.J. (2016). Adaptive fuzzy optimal control using direct heuristic dynamic programming for 
chaotic discrete-time system. Journal of Vibration and Control, 22(2): 595-603 https://doi.org/10.1177/1077546314534286

[22] Zhang, X.G., Chen, H., Zhang, J., Liu, X.Y. (2007). Intelligent predictive control strategy applied to sintering temperature in rotary kiln based on image feedback. Control Theory \& Applications, 6 .

[23] Hagemoen, S.W. (1993). An expert system application for lime kiln automation. Conference Record of 1993 Annual Pulp and Paper Industry Technical Conference, Hyannis, MA,

USA. https://doi.org/10.1109/PAPCON.1993.255821

[24] Järvensivu, M., Saari, K., Jämsä-Jounela, S.L. (2001) Intelligent control system of an industrial lime kiln process. Control Engineering Practice, 9(6): 589-606. https://doi.org/10.1016/S0967-0661(01)00017-X

[25] Anand, S.K., Sundara Raman, T.G., Subramanian, S. (2014). Implementing a neuro fuzzy expert system for optimising the performance of chemical recovery boiler. International Journal of Artificial Intelligence and Soft Computing, $4(2-3)$ : 249-263. https://doi.org/10.1016/S0952-1976(01)00033-1

[26] Zhou, X., Chai, T. (2007). Pattern-based hybrid intelligent control for rotary kiln process. 2007 IEEE International Conference on Control Applications, Singapore. https://doi.org/10.1109/CCA.2007.4389201

[27] Lu, X., Kiumarsi, B., Chai, T., Lewis, F.L. (2016). Data-driven optimal control of operational indices for a class of industrial processes. IET Control Theory and
Applications 10(12):

$1348-1356$

https://doi.org/10.1049/iet-cta.2015.0798

[28] Elliriki, M., Reddy, C., Anand, K. (2019). An efficient line clipping algorithm in 2D Space. International Arab Journal of Information Technology, 16(5): 798-807.

[29] Krishna Anand, S., Kalpana, R., Vijayalakshmi, S. (2013). Design and Implementation of a fuzzy expert system for detecting and estimating the level of asthma and chronic obstructive pulmonary disease. World Applied Sciences Journal, 23: 213-223. https://doi.org/10.5829/idosi.wasj.2013.23.02.13046

[30] Kumar, J.P., Ray, A.K., Mitra, R. (2009). Model predictive control of lime Kiln; A costeffective strategy. IPPTA: Quarterly Journal of Indian Pulp and Paper Technical Association, 21(3).

[31] Anand, S.K., Pratyusha, M., Mounica, C., Vineesha, K. (2014). Design and analysis of a back propagation neural network in estimating risk of coronary artery disease. American-Eurasian Journal of Scientific Research, $9(1)$ : $16-25$. https://doi.org/10.5829/idosi.aejsr.2014.9.1.1136

[32] Zhang, L., Xu, S.Z., Zhao, H.T. (2014). Adaptive subspace predictive control with time-varying forgetting factor. International Journal of Automation andComputing, 11(12): 205-209.

[33] Gürtürk, M., Oztop, H.F., Pambudi, N.A. (2018). CFD analysis of a rotary kiln using for plaster production and discussion of the effects of flue gas recirculation application. Heat and Mass Transfer, 54(10): 2935-2950. 